\title{
Does Forehand Racquet Handgrip influence Incidence and Type of Wrist Injury in Tennis? A Preliminary Study in Indian Tennis
}

\author{
${ }^{1}$ Sharad Prabhakar, ${ }^{2}$ Mandeep S Dhillon, ${ }^{3}$ Dharam S Meena, ${ }^{4}$ Himmat Dhillon, ${ }^{5}$ Sidak Dhillon
}

\begin{abstract}
Introduction: Tennis is one of the major global sports, with over 75 million players participating in the game in more than 200 countries affiliated with the International Tennis Federation. The upper extremity is particularly susceptible to injury in tennis because of the use of the racquet, which acts as a lever, and due to the effect of repetitive stroke play on the dominant limb.

Materials and methods: Between July 2009 and October 2010 , in a prospective study involving players at a local tennis academy, 219 tennis players were evaluated for wrist injury. A specialized injury proforma was filled up for these players and parameters, such as injury type, mechanism of injury, forehand racquet grip (eastern, western and semiwestern), missed time from game, and treatment (medical or surgical) were recorded. The players were grouped into low-intensity players (those with average daily practice hours $<2.5$ ) and high-intensity players (with $\geq 2.5$ daily average practice hours). Statistical analysis was performed to assess the association of different wrist injuries with type of forehand handgrip.
\end{abstract}

Results: Out of 219 players, 14 players were lost to follow-up. Out of the remaining 205 players, a total of 157 (76\%) players were aware of the type of handgrip they were using, while 18 (9\%) players did not have any knowledge of their handgrip. The remaining $30(15 \%)$ players were found to be confused as far as handgrip was concerned. Out of 157 players who had knowledge regarding handgrip, 102 players were using the semiwestern grip, 44 were using the western grip, and the remaining 11 were using the eastern type of handgrip. There were seven injuries sustained in the wrist and hand. Due to the relatively small number of wrist injury cases, no statistical correlation could be derived between handgrip use and specific injuries in the upper limb.

Conclusion: In tennis players with wrist injuries, different grips of the racquet are not related to the anatomical site of the

\footnotetext{
${ }^{1}$ Associate Professor, ${ }^{2}$ Professor and Head, ${ }^{3}$ Former Resident ${ }^{4}$ Physiotherapist, ${ }^{5}$ Postgraduate Student

${ }^{1-3}$ Department of Orthopedics, Postgraduate Institute of Medical Education and Research, Chandigarh, India

${ }^{4}$ Department of Physiotherapy, Flinders University, Adelaide Australia

${ }^{5}$ Department of Sports Medicine and Arthroscopy, Sri Ramachandra Medical College and Research Institute, Chennai Tamil Nadu, India

Corresponding Author: Mandeep S Dhillon, Professor and Head, Department of Orthopedics, Postgraduate Institute of Medical Education and Research, Chandigarh, India, Phone: +919815951090, e-mail: drdhillon@gmail.com
}

lesion. Previous studies have correlated the type of handgrip with the pattern of wrist injuries. Though we have 219 players in our study, the players who sustained wrist injuries were less (7). Thus, we were unable to find any correlation between type of handgrip and pattern of wrist injuries. Further studies are required so as to understand the biomechanics of tennis injuries.

Keywords: Handgrip, Injury, Racquet, Tennis.

How to cite this article: Prabhakar S, Dhillon MS, Meena DS, Dhillon H, Dhillon S. Does Forehand Racquet Handgrip influence Incidence and Type of Wrist Injury in Tennis? A Preliminary Study in Indian Tennis. J Postgrad Med Edu Res 2018;52(1):1-4.

Source of support: Nil

Conflict of interest: None

\section{INTRODUCTION}

Tennis is one of the major global sports, with over 75 million players participating in the game in more than 200 countries affiliated with the International Tennis Federation. ${ }^{1}$ Tennis places strenuous physical stresses on the players, requiring them to move quickly in all directions with frequent direction changes and sudden stops and starts while also maintaining balance, control, and coordination with the upper body strength to hit the ball effectively. ${ }^{2}$ The upper extremity is particularly susceptible to injury in tennis because of the use of the racquet, which acts as a lever, and due to the effect of repetitive stroke play on the dominant limb. ${ }^{3}$ Tennis is a noncontact sport; however, the highly repetitive nature of the game with long playing hours and the use of a long racquet can cause injuries to the wrist. Very limited data are available about the type of handgrip that a tennis player employs and its correlation with the injury profile of the hand and the wrist. ${ }^{4}$

\section{MATERIALS AND METHODS}

Between July 2009 and October 2010, in a prospective study involving players at a local tennis academy, 219 tennis players were evaluated for wrist injury. A specialized injury proforma was filled up for these players to document all parameters including injury mechanism, injury site, type of forehand grip (eastern, western and semiwestern), missed time from game, and treatment. The players were grouped into low-intensity players 

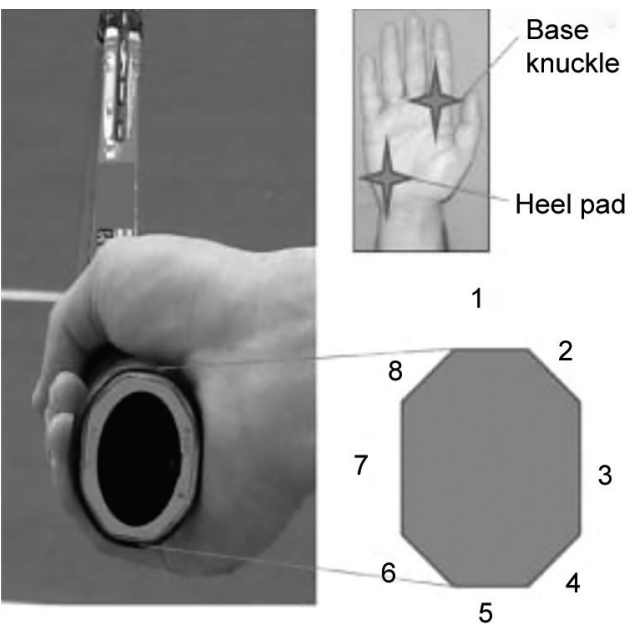

Fig. 1: Tennis handgrips in relation with the racquet

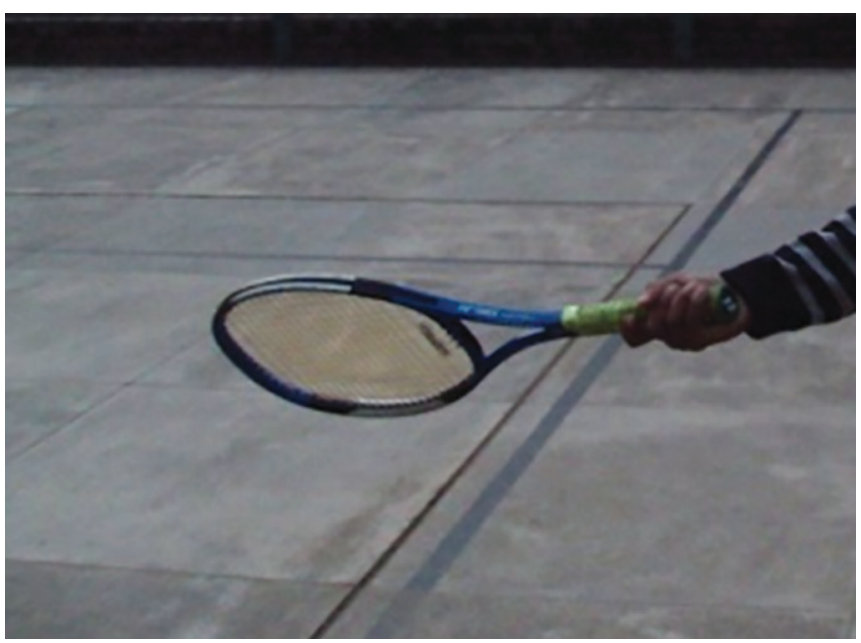

Fig. 3: Player using semiwestern handgrip

(those with average daily practice hours $<2.5$ ) and high-intensity players (with $\geq 2.5$ daily average practice hours). Statistical analysis was performed to assess the association of different wrist injuries with type of forehand handgrip.

\section{Tennis Handgrip}

Tennis players use mainly three types of forehand grip to hit the ball. The grips are defined based on the location of the base knuckle of the index finger on the eight faces of the racquet grip (Fig. 1).

Eastern grip: In the eastern grip, the base knuckle is on face 3, and the heel pad between 2 and 3 (Fig. 2).

Semiwestern grip: The semiwestern forehand grip has the base knuckle and the heel pad on face 4. This grip ensures strength and control to the forehand (Fig. 3).

Western grip: In this grip, both the base knuckle and the heel pad are located on face 5 . This grip originated on the bouncier cement courts of the western world. This is excellent for high balls and top-spin, but is difficult for low balls and under-spin (Fig. 4).

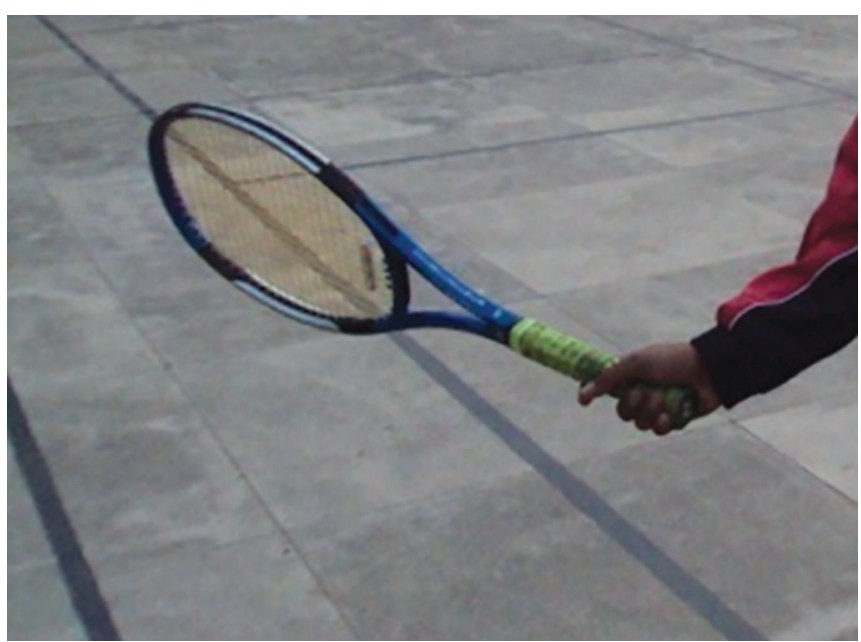

Fig. 2: Player using eastern handgrip

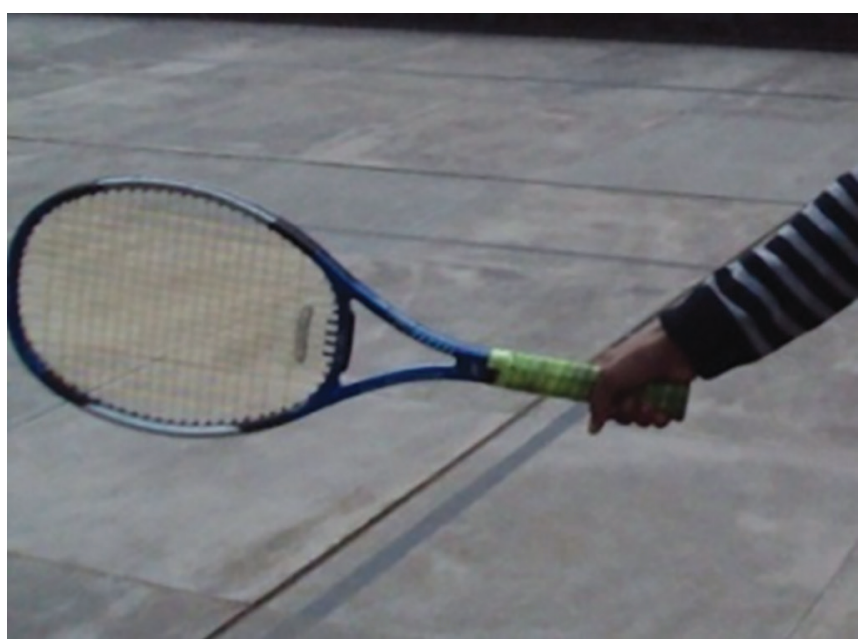

Fig. 4: Player using western handgrip

\section{RESULTS}

Out of 219 players, 14 players were lost to follow-up. Out of the remaining 205 players, a total of 157 (76\%) players were aware of the type of handgrip they were using, while $18(9 \%)$ players did not have any knowledge of their handgrip. The remaining $30(15 \%)$ players were found to be confused as far as handgrip was concerned (Graph 1). Out of 157 players who had knowledge regarding their handgrip, 102 players were using semiwestern grip, 44 were using western grip, and the remaining 11 were using eastern type of handgrip (Graph 2). There were 82 low-intensity players while 75 were high-intensity players. Among the high-intensity players, 44 were using the western grip while 31 were using the semiwestern handgrip. Among the low-intensity players, 71 were using the semiwestern grip and 11 were using the eastern type of handgrip.

There were a total of seven injuries present in the wrist and hand. Bilateral wrist pain on ulnar aspect was present in one high-intensity player. He was playing with western handgrip; clinically there was tenderness over 


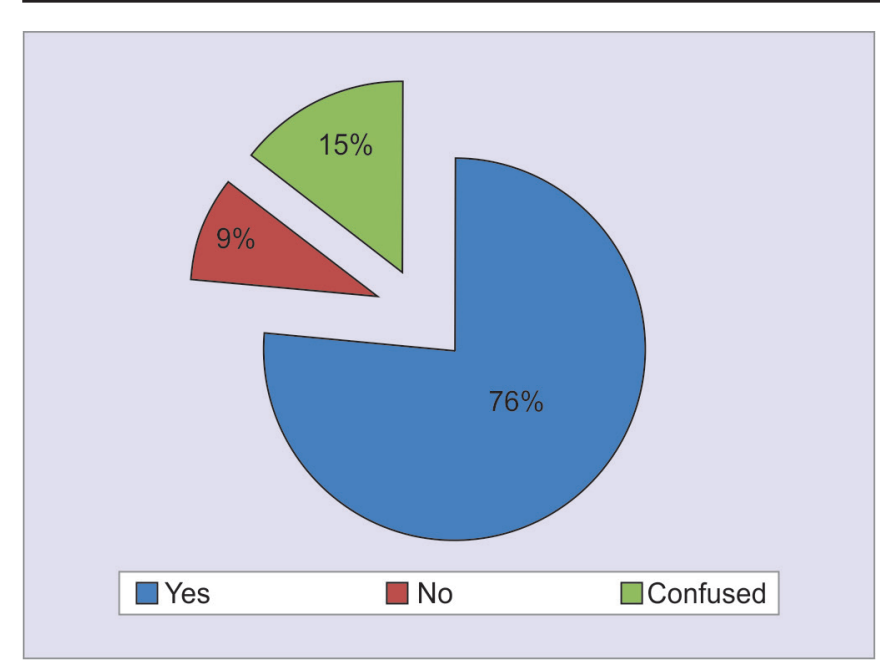

Graph 1: Knowledge of handgrip

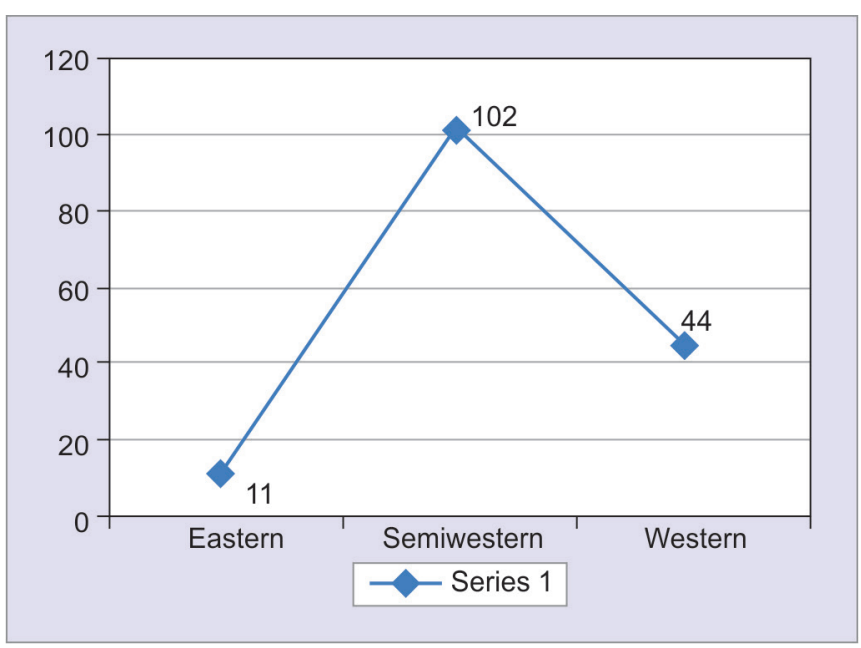

Graph 2: Distribution of different handgrips anterior aspect of wrist joint. Radiographs were normal. The player was diagnosed with flexor carpi ulnaris tendonitis. Analgesics were given along with wrist brace, and he resumed his practice after 3 weeks.

Another low-intensity player was diagnosed with scaphoid fracture following fall on the outstretched hand. He was advised surgery. He, however, declined and gave up playing tennis. He was also not available for any subsequent follow-up.

Three players (one high-intensity player, two lowintensity players) using the semiwestern grip were diagnosed with extensor carpi ulnaris tendonitis. However, they were only mildly symptomatic, did not need analgesics or a brace, and the pain spontaneously resolved. There was no match time lost.

One low-intensity player using the eastern grip had nonspecific wrist pain, which resolved over 2 days with analgesics. Due to the small number of wrist injury cases, no statistical correlation could be derived between handgrip use and specific injuries in upper limb.

\section{DISCUSSION}

We have documented three types of forehand grip in our players. Around $76 \%$ of players were aware about their grip type, while many players were either confused $(15 \%)$ or did not have knowledge (9\%) about handgrip. Out of these players, $65 \%$ players were using semiwestern grip, 28\% were using western grip, and remaining $7 \%$ players were using eastern type grip. A literature review showed only one study done by Tagliafico et $\mathrm{al}^{4}$ regarding the relation of wrist injuries with different types of grip, in which $77 \%$ players used western or semiwestern grip, while $23 \%$ players used eastern grip. Ulnar-sided injuries were usually associated with western or semiwestern grips while radial-sided injuries were associated with eastern grip. The authors did not find any association between the type of grip used and elbow or shoulder injuries.

We also analyzed the injury type and its relation with the handgrip type, but we could find no correlation. The injuries to the wrist noted in our study were all nonspecific, except one scaphoid fracture, which was caused by a fall on the outstretched hand and was unrelated to the type of grip used.

Due to the constant use of the racquet, wrist injuries are quite common in tennis; these could potentially range from tendinitis to stress fracture of carpal bones. ${ }^{5}$ The major mechanism of wrist injury in racquet sports is "persistent repetitive controlled force" causing tendinitis and other overuse injuries. ${ }^{5}$ Nevertheless, injuries can occur from direct trauma (e.g., a fracture from a fall or a hit by a racquet) or from sudden, uncontrolled excessive force. The direct impact of the racquet handle and the repetitive forceful whipping of the wrist in stroke play have the potential to cause a wide range of soft tissue injuries to players' hands and wrists. ${ }^{5}$

A surprising report by Kibler and Chandler ${ }^{6}$ stated that wrist tendonitis is uncommon in tennis; it is usually seen either in very advanced players who use more wrist motion to respond to hard shots or create shots, or in beginners who use wrist motion because of poor stroke mechanics. Our literature review could neither authenticate nor disprove this fact, as wrist biomechanics in tennis are not very well studied in the current publications on record.

\section{CONCLUSION}

In tennis players with wrist injuries, different grips of the racket are not related to the anatomical site of the lesion. Previous studies have shown a correlation between type of grip and specific pattern of wrist injuries. Though we have 219 players in our study, the players who sustained 
wrist injuries were less (7); this may be the factor because of which we were unable to find the correlation between types of handgrip and pattern of wrist injuries. Further studies are required so as to understand the biomechanics of tennis injuries.

\section{REFERENCES}

1. Pluim BM, Miller S, Dines D, Renström P, Windler G, Norris B, Stroia K, Donaldson A, Martin K. Sport science and medicine in tennis. Br J Sports Med 2007 Nov;41(11):703-704.

2. Chandler TJ. Exercise training for tennis. Clin J Sport Med 1995 Jan;14(1):33-46.
3. Marks MR, Haas SS, Wiesel SW. Low back pain in the competitive tennis player. Clin J Sport Med 1988 Apr;7(2):277-287.

4. Tagliafico AS, Ameri P, Michaud J, Derchi LE, Sormani MP, Martinoli C. Wrist injuries in nonprofessional tennis players: relationships with different grips. Am J Sports Med 2009 Apr;37(4):759-767

5. Osterman AL, Moskow L, Low DW. Soft tissue injuries of the hand and wrist in racquet sports. Clin J Sport Med 1988 Apr;7(2):329-348.

6. Kibler, WB.; Chandler, TJ. Racquet sports. In: Fu FH, Stone DA, editors. Sports injuries. Mechanisms, prevention and treatment. Baltimore (MD): Williams and Wilkins publications; 1994. p. 117-120. 